\title{
Effects of Intimate Marital Relationships Upon Self-Reported Rearing Styles Among Japanese Parents of Young Children
}

\author{
Xi Lu, Masayo Uji and Toshinori Kitamura* \\ Department of Clinical Behavioural Sciences (Psychological Medicine), Kumamoto University Graduate School of \\ Medical Sciences, Japan
}

\begin{abstract}
In order to examine the effects of intimate marital relationships upon self-reported rearing styles towards a young child, 118 Japanese couples with at least one child were administered a set of questionnaires. A path analysis showed that wives whose husbands treated them with an affectionate attitude were more likely to hold affectionate childrearing styles; wives whose husbands treated them with a controlling attitude were more likely to hold overprotective child-rearing styles; husbands whose wives acted in controlling ways towards them tended to exhibit less affectionate and more overprotective rearing child-rearing practices.
\end{abstract}

\section{INTRODUCTION}

Parental child-rearing styles are important in part because they relate to the development of personality [1-7] and the onset of different types of mental disorders [8-17] among children. The issue of how to achieve optimal rearing patterns in parents is an important one in educational and clinical settings.

This leads to a research question: How do rearing styles develop? Parental attitudes towards their child may be influenced by genetic predisposition [18-26], personality [19, 26, 27], maternal depression [28-32] and other variables.

One further candidate is perceived marital intimacy. The past literature [33-35] suggests both the compensatory and spillover hypotheses. In the former, it is suggested that a parent whose needs for love and intimacy are not met in the marital relationship seeks to satisfy these needs in the parentchild relationship. On the other hand, the spillover hypothesis proposes that the quality of the marriage, whether good or bad, "spills over" and affects the parent-child relationship. Poor parenting has been listed as a mediator of the effects of marital conflict on child maladjustment [36]. Parents who experience marital strife may find it difficult to maintain consistent and adequate parenting techniques [37-38], while those who are absorbed in their conflicts may be less involved in parenting practices. Thus, parents who perceive their spouse's attitude towards them as affectionate and less demanding may show a similarly affectionate and less demanding attitude towards their own child. A meta-analysis supports the spillover hypothesis [33]. However, most of the past literature used families in the Western countries. Little has been studied in the Eastern countries such as Japan.

Another drawback of the past literature is the inconsistency between assessments of the marital relationship and

*Address correspondence to this author at the Department of Clinical Behavioral Sciences (Psychological Medicine), Kumamoto University, Graduate School of Medical Sciences, 1-1-1 Honjo, Kumamoto, Japan 860-8556; Tel: +81-96-373-5183; Fax: +81-96-373-5181;

E-mail: kitamura@kumamoto-u.ac.jp that of the parent-child relationship. Researchers [e.g., 3941] used measures of marital relationship such as the Dyadic Adjustment Scale, the Marital Adjustment Test, and the Personal Assessment of Intimacy in Relationship Questionnaire, and measures of parent-child relationship such as the Child Report of Parental Behavior Inventory, the Parenting Stress Index, and the Parental Locus of Control Scale. These measures were developed on different conceptual grounds thus lacking theoretical consistence of subscales of marital and parent-child relationships.

This study is a preliminary report on the effects of intimate marital relationships upon parents' attitudes towards their children in a Japanese population. We used two measures, one for marital relationship and another for parent-child relationship based on the same theoretical basis --- care and control. We hypothesized that the marital relationship would influence the parent-child relationship on the same domain.

\section{METHOD}

\section{Participants}

We solicited participation in this questionnaire-based study from the employees of an education company in Kyoto. Seventy-five couples agreed to participate. We then asked these couples to ask their acquaintances to take in part (if they were eligible). This resulted in the participation of 176 couples. These couples were either handed or mailed the questionnaire. The questionnaires for husbands and wives were put into separate envelopes, and the couple was asked to fill in the forms independently and return them anonymously to the researchers. Of the 176 initially eligible couples, 118 provided complete data from both husband and wife and were therefore included in further analyses.

The participants' mean (SD) age was 35.4 (5.1) years for fathers and 34.4 (5.2) years for mothers. The mean (SD) duration of marriage was 7.0 (4.0) years. Five fathers and two mothers were remarried. Education at university level or higher was reported by $81(69 \%)$ of fathers and $91(77 \%)$ of mothers. 
The number of children per family was one for $55(47 \%)$ families, two for 47 (40\%) families, three for 15 (13\%) families and 4 for one family. Of these 198 children, there were 107 boys and 91 girls. The mean (SD) age of the youngest child was 2.8 (2.4) years with a range between 0 and 10 years. The mean (SD) age of the oldest child was 4.8 (4.0) years with a range between 0 and 27 years.

\section{Measurements}

Parents' parenting styles: We used the Parental Bonding Instrument (PBI) [42]. The PBI was originally developed as a measure to assess retrospectively how an individual perceived their father's and mother's parenting (separately) before they were aged 16. In this study, however, parents were asked to rate their own parenting style. Thus, the tense of sentences was rephrased into the present and the subject of sentences into "I". Such a modification was proposed by Parker, Fairley, Greenwood, Jurd, \& Silove [9]. Parker [12] suggested two subscales: Care and Overprotection. Care items (12 items on a 4-point scale: 0 to 3 points) reflect a parenting style that may range from coldness, indifference and neglect, to affection, emotional warmth, empathy, and reciprocity. Examples are "spoke to me with a warm and friendly voice," and "frequently smiled at me." Overprotection items (13 items on a 4-point scale) reflect a parenting style that may range from parental control and overprotection, intrusion and infantilization to parental allowance, independence, and the development of autonomy. Examples are "invaded my privacy," and "tried to make me dependent on him." The PBI has been demonstrated to have good validity [12]. The Japanese version of this scale was developed by Kitamura and Suzuki [43]. Uji, Tanaka, Shono, \& Kitamura [44] have demonstrated that the factor structure of the PBI among a Japanese population is virtually the same as that reported by Parker [12]. In this study, missing values of the PBI items were substituted with the mean of the item only for those cases in which less than 7 items were missing.

Marital intimate relationships: We used the Intimate Bond Measure (IBM) [45]. This is a self-report measure for evaluating a marital partner's attitudes in two dimensions: Care and Control. Each dimension is rated with 12 items on a 4-point scale: 0 to 3 points. These two dimensions correspond to the two dimensions of the PBI. The IBM Care scores have been shown to be lower among individuals with non-melancholic depression [46-47] and post-natal depression [48], and predict poorer outcome of depression [49]. In this study, missing values of the IBM items were substituted with the mean of the item only for those cases in which less than 7 items were missing.

\section{Procedure}

The set of questionnaires including the PBI, IBM and other items (not reported in this paper) were distributed to parents, and they were asked to fill and return them directly to the researchers using a stamp added envelope. The study responses were anonymous. However, in order to link the responses of members of the same couple, a serial number was added to the study face sheet.

This research project was approved by the Ethical Committee of Kumamoto University Graduate School of Medical Sciences.

\section{Statistical Analyses}

First, we calculated means and SDs of all the variables used in this study and also correlated all the variables. Because we were interested in whether intimate marital relationships would influence the couples' parenting styles, we created a path analysis model in which all the IBM scores were expected to influence any of the PBI scores.

Proceeding from the bivariate analyses of the present sample as well as the past literature, we expected covariances between any combination of all the IBM scores and between any combinations of all the PBI error scores. It is of note that because AMOS does not allow positing a covariance between endogenous variables, we posited covariances between the error variables of such variables. Structural equation models were improved by deleting covariances without statistical significance $(p>.05)$.

The fit of each model with the data was examined in terms of chi-squared (CMIN), goodness-of-fit index (GFI), adjusted goodness-of-fit index (AGFI), comparative fit index (CFI), and root mean square error of approximation (RMSEA). According to conventional criteria, a good fit would be indicated by CMIN $/ \mathrm{df}<2$, GFI $>.95$, AGFI $>.90$, CFI $>.97$, and RMSEA $<.05$; an acceptable fit by CMIN $/ \mathrm{df}<3$, GFI $>.90$, AGFI $>.85, \mathrm{CFI}>.95$, and RMSEA $<.08$ [50].

We conducted all the statistical analyses using the Statistical Package for Social Science (SPSS) version 14.0 and Amos 6.0.

\section{RESULTS}

The means and SDs of all the variables used in this study as well as their bivariate zero-order correlations are in Table $\mathbf{1}$.

As expected from the literature, the two PBI subscale scores - Care and Overprotection - were significantly correlated among mothers (Table 1). The Care and Overprotection scores were correlated between fathers and mothers, respectively. Similarly, the two IBM subscale scores - Care and Control - were significantly correlated among fathers and mothers. The Care scores were correlated between fathers and mothers.

The fathers' and mothers' Care towards their child were correlated to their spouse's Care towards them. The fathers' and mothers' Overprotection towards their child were correlated to their spouse's Control towards them. In addition, fathers' Care towards their child was correlated with their spouse's low Control towards them.

The revised path analysis model has shown that fathers' Care towards wife influences mothers' Care towards the child; fathers' Control towards wife influences mothers' Overprotection towards the child; mothers' Control towards husband influences fathers' low Care and Overprotection towards their child (Fig. 2). Mothers' Care towards husband failed to show significant influence to parental styles. This model fit the data very well. $\mathrm{CMIN} / \mathrm{df}=0.72 ; \mathrm{GFI}=.982$; $\mathrm{AGFI}=.947 ; \mathrm{CFI}=1.000 ; \mathrm{RMSEA}=0.00$.

\section{DISCUSSION}

This study has shown that parents' attitudes towards a child are to some extent influenced by their spouses' intimate attitudes towards them. The spillover hypothesis was supported to some extent among a Japanese population. 


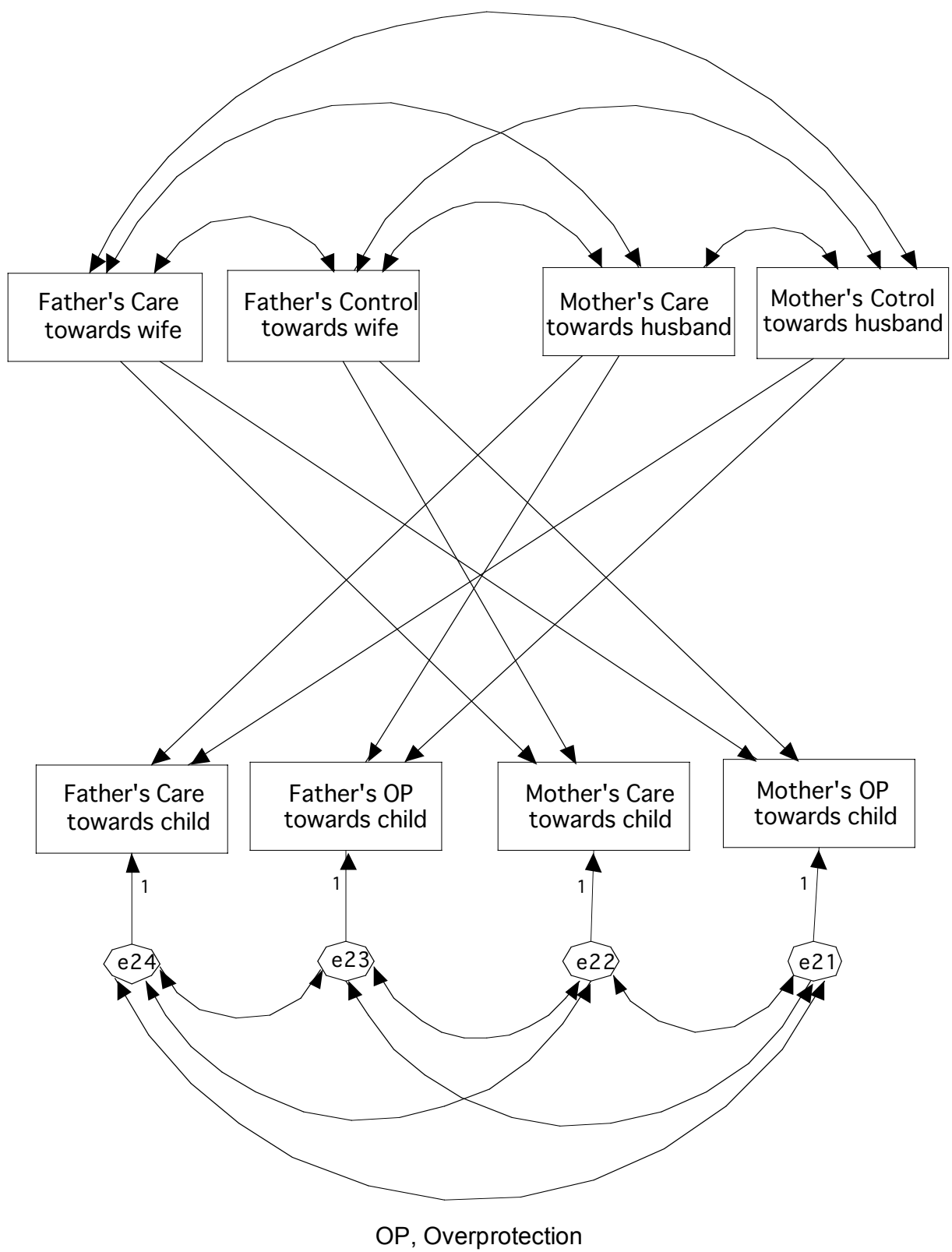

Fig. (1). Model describing the relationship between intimate marital relationships and parents' child-rearing styles.

Table 1. Correlations Between and Means and SDs of the Variables Used in the Present Study $(N=118)$

\begin{tabular}{|c|c|c|c|c|c|c|c|c|}
\hline & 1 & 2 & 3 & 4 & 5 & 6 & 7 & 8 \\
\hline 1. PBI: Father's Care towards child & --- & & & & & & & \\
\hline 2. PBI: Father's OP towards child & -.03 & --- & & & & & & \\
\hline 3. IBM: Father's Care towards wife & $.19 *$ & -.09 & --- & & & & & \\
\hline 4. IBM: Father's Control towards wife & .04 & -.08 & $-.26 * *$ & --- & & & & \\
\hline 5. PBI: Mother's Care towards child & $.24 * *$ & .02 & $.42 * * *$ & -.08 & --- & & & \\
\hline 6. PBI: Mother's OP towards child & .19 & $.25 * *$ & -.13 & $.19 *$ & $-.22 *$ & --- & & \\
\hline 7. IBM: Mother's Care towards husband & $.28 * *$ & -.06 & $.52 * * *$ & $-.29 * *$ & $.24 *$ & -.08 & --- & \\
\hline 8. IBM: Mother's Control towards husband & $-.30 * *$ & $.19 *$ & $-.41 * * *$ & .14 & -.14 & .05 & $-.51 * * *$ & --- \\
\hline Mean & 29.2 & 14.5 & 26.6 & 10.9 & 28.5 & 14.5 & 27.9 & 12.7 \\
\hline SD & 3.8 & 4.6 & 6.6 & 5.6 & 4.5 & 4.3 & 6.5 & 6.6 \\
\hline
\end{tabular}

OP, Overprotection; $* \mathrm{p}<.05 ; * * \mathrm{p}<.01 ; * * * \mathrm{p}<.001$. 


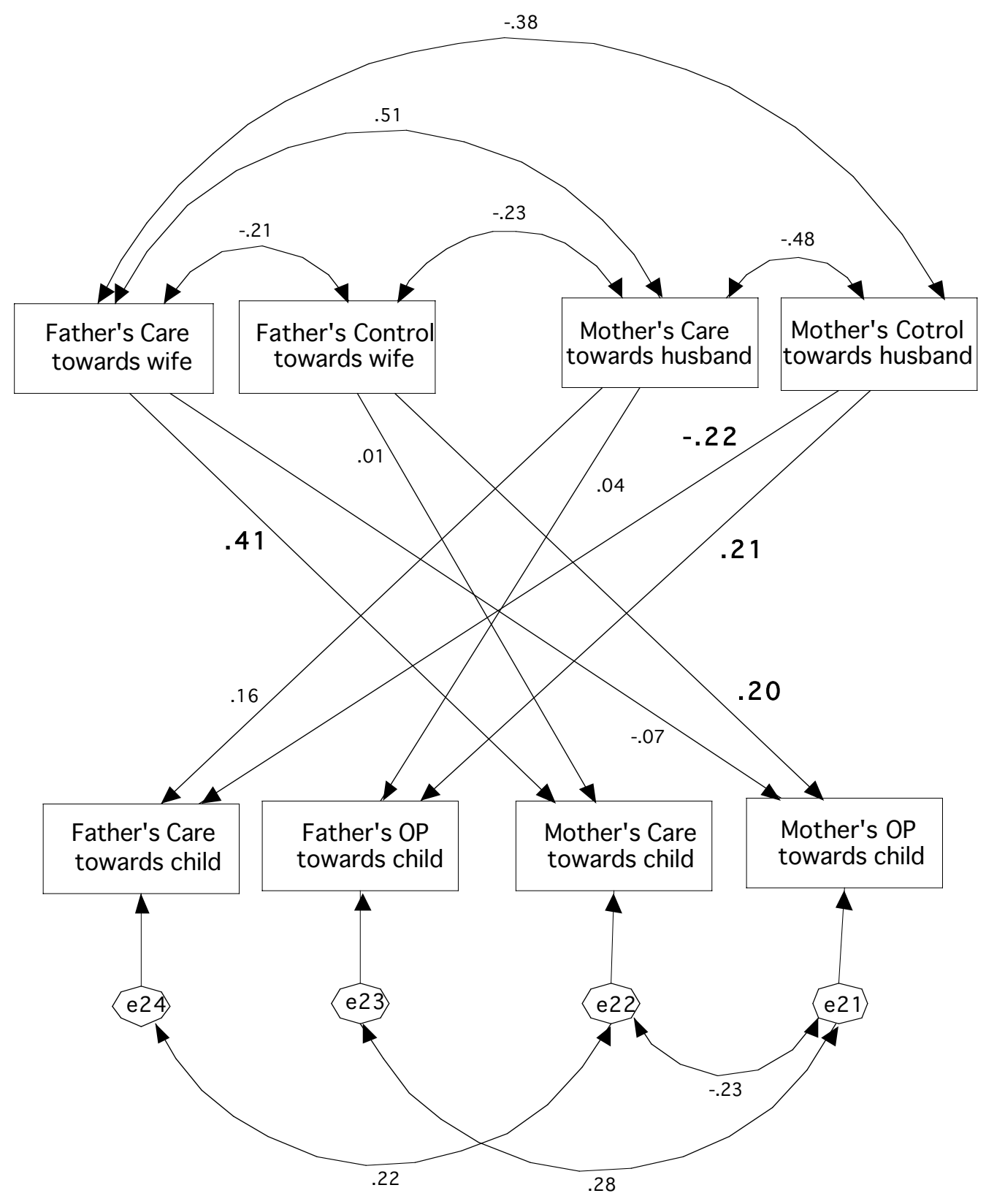

CHI-SQUARED $=8.688$

$\mathrm{df}=12$

$\mathrm{GFI}=.982$

$\mathrm{AGFI}=.947$

$\mathrm{CFI}=1.000$

RMSEA $=.000$

$\mathrm{AIC}=56.688$

OP, Overprotection; coefficients in bold signifies statistical significance $(p<.05)$

Fig. (2). Revised model describing the relationships between intimate marital relationships and parents' child-rearing styles.

The strength of the present study is the use of two measures - PBI and IBM - that were developed based on the same constructs - Care and Overprotection (Control). Our results showed that fathers' affectionate relationship with their wives promotes an affectionate relationship between mother and child. Fathers' controlling attitude towards their wives promotes an overprotective relationship between mother and child. Similarly, mothers' controlling relationship with their husbands contributes to the fathers' controlling relationship with the child. In addition, mothers' less controlling relationship with husbands encourages the fathers' affectionate relationship with a child.

\section{Limitations of the Study}

Limitations of this study should be discussed. A drawback of this study is the use of self-report for the measure- 
ment of both child-rearing attitudes and perceived attitudes of the spouse towards the participant. Social desirability may confound spurious correlations. However, Robinson and Anderson [51] reported that the significant correlation between the marital adjustment and spousal attitudes both based on self-reports would not be reduced even after controlling for the effects of social desirability.

Another drawback of this study is its cross-sectional design. The causal relationship we hypothesized in this study may be reversed. Alternatively, individuals may have personality traits that determine both their attitudes towards spouses and children.

The relationship between the marital intimacy and childrearing styles may be confounded by children's behaviors. For example, children's attachment styles to caregivers are linked to the parental attitudes towards the children [52]. Eleven-month-old infants glance at fathers more frequently if the fathers are satisfied with their marriage [53]. Three- to four-year-old daughters of less martially satisfied parents are less compliant with their fathers [54]. The present study did not examine the children's temperament or behaviors thus cannot address this issue.

The correlation between the marital relationship and child-rearing styles may also be confounded by the type of rearing the parents received during their childhood. Better marital adjustment was reported to be linked to spouses receiving high care and low overprotection as children [55]. As noted in the Introduction, research suggests that parents rear their child as they were reared as a child and that this may be to some extent be explained genetically. Thus, the links suggested in this study may be spurious.

This study needs caution in interpretation because this was a convenient sample. The present sample was characterized by young age and higher education. This may make it difficult to generalize the results. Populations with other characteristics should be examined before reaching a conclusion. A clinical population may also be a target of research of this kind.

\section{CONCLUSION}

This study has suggested that the marital relationship exerts influences on the parent-child relationship in a Japanese population. This relationship may, to some extent, be specific to domains (Care and Control) of relationships.

\section{REFERENCES}

[1] Benjaminsen S, Jorgensen J, Kragh-Hansen L, Pedersen LL. Memories of parental rearing practices and personality features. Acta Psychiatr Scand 1984; 69: 426-34.

[2] Kendler KS, Kessler RC, Neale MC, Heath AC, Eaves LJ. The prediction of major depression in women: toward an integrated etiologic model. Am J Psychiatry 1993; 150: 1139-48.

[3] Kitamura T, Fujihara S. Understanding personality traits from early life experiences. Psychiatry Clin Neurosci 2003; 57: 323-31.

[4] Kitamura T, Tomoda A, Kijima N, Sakamoto S, Tanaka E, Iwata N. Correlates of retrospective early life experience with personality in young Japanese women. Psychol Rep 2002; 91: 263-74.

[5] Ono Y, Yoshimura K, Mizushima H, et al. Environmental and possible genetic contributions to character dimensions of personality. Psychol Rep 1999; 84: 689-96.

[6] Ruchkin VV, Eisemann M, Hägglöf B, Cloninger CR. Interrelations between temperament, character, and parental rearing in male delinquent adolescents in Northern Russia. Comp Psychiatry 1998; 39: $225-30$.
[7] Reti IM, Samuels JF, Eaton WW, Bienvenu OJ III, Costa PT Jr, Nestadt G. Influence of parenting on normal personality traits. Psychiatr Res 2002; 111: 55-64.

[8] Onstad S, Skre I, Togerses S, Kringlen E. Family interaction: parental representation in schizophrenic patients. Acta Psychiatr Scand 1994; 384: 67-70

[9] Parker GB, Fairley M, Greenvood J, Jurd S, Silove D. Parental representations of schizophrenics and their association with onset and course of schizophrenia. Br J Psychiatry 1982; 141: 573-81.

[10] Murphy E, Brewin C, Silka L. The assessment pf parenting using Parental Bonding Instrument: two or three factors? Psychol Med 1997; 27: 333-42.

[11] Parker G. Parental characteristics in relation to depressive disorders. Br J Psychiatry 1979; 134: 138-47.

[12] Parker GB. Parental overprotection: A risk factor in psychosocial development. New York: Grune and Stratton, 1983.

[13] Rey JM. Perceptions of poor maternal care are associated with adolescent depression. J Affect Dis 1995; 34: 95-100.

[14] Rodriguez Vega B, Bayon C, Franco B, Canas F, Gaell M, Salvador M. Parental rearing and intimate relationships in woman's depression. Acta Psychiatr Scand 1993; 88: 192-7.

[15] Sato T, Sakado K, Uehara T, Nishikawa K, Kasahara Y. Perceived parental styles in a Japanese sample of depressive disorders: a replication outside Western culture. Br J Psychiatry 1997; 170: 173-5.

[16] Sato T, Uehara T, Sakado K, et al. Dysfunctional parenting and a lifetime history of depression in a volunteer sample of Japanese workers. Acta Psychiatr Scand 1997; 96: 306-10.

[17] Uehara T, Sato T, Sakado K, Someya T. Parental Bonding Instrument and the Inventory to Diagnose Depression Lifetime version in a volunteer sample of Japanese workers. Depress Anxiety 1998; 8: 65-70.

[18] Kendler KS. Parenting: A genetic-epidemiologic perspective. Am J Psychiatry 1996; 153: 11-20.

[19] Lichtenstein P, Ganiban J, Neiderhiser JM, et al. Remembered parental bonding in adult twins: Genetic and environmental influences. Behav Genet 2003; 33: 397-408.

[20] Herndon RW, McGue M, Krueger RF, Iacono WG. Genetic and environmental influences on adolescents' perceptions of current family environment. Behav Genet 2005; 35: 373-80.

[21] Neiderhiser JM, Reiss D, Pedersen NL, et al. Genetic and environmental influences on mothering of adolescents: A comparison of two samples. Dev Psychol 2004; 40: 335-51.

[22] Wade TD, Kendler KS. The genetic epidemiology of parental discipline. Psychol Med 2000; 30: 1303-13.

[23] Walden B, McGue M, Iacono WG, Burt SA, Elkins I. Identifying shared environmental contributions to early substance use: The respective roles or peers and parents. J Abnorm Psychol 2004; 113: $440-50$

[24] Boivin M, Perusse D, Dionne G, et al. The genetic-environmental etiology of parents' perceptions and self-assessed behaviours toward their 5-month-old infants in a large twin and singleton sample. J Child Psychol Psychiatry 2005; 46: 612-30.

[25] Deater-Deckard K, Dunn J, O'Connor TG, Davies L, Golding J, and the ALSPAC Study Team. Using the stepfamily genetic design to examine gene-environment processes in child and family functioning. Marriage Fam Rev 2001; 33: 131-56.

[26] Spinath FM, O'Connor TG. A behavioral genetic study of the overlap between personality and parenting. J Pers 2003; 71: 785-808.

[27] Myers LB, Brewin CR, Winter DA. Repressive coping and selfreport of parenting. Br J Clin Psychol 1999; 38: 73-82.

[28] Fleming AS, Ruble DN, Flett GL, Shaul DL. Postpartum adjustment in first-time mothers: Relations between mood, maternal attitudes, and mother-infant interactions. Dev Psychol 1988; 24: 7181 .

[30] Leiferman JA, Ollendick TH, Kunkel D, Christie IC. Mothers' mental distress and parenting practices with infants and toddlers. Arch Women Ment Health 2005; 8: 243-7.

[31] McLearn KT, Minkovitz CS, Strobino D, Marks E, Hou W. Maternal depressive symptoms at 2 to 4 months post partum and early parenting practices. Archiv Pediat Adolesc Med 2006; 160: 279-84

[32] Siomons RL, Lorenz FO, Wu C-I, Conger RD. Social network and marital support as mediators and moderators of the impact of stress and depression on parental behavior. Dev Psychol 1993; 29: 368 81 
[33] Erel O, Burman B. Interrelatedness of marital relations and parentchild relations: A meta-analytic review. Psychol Bull 1995; 118: 108-32.

[34] Fincham F, Grych JH, Osborne LN. Does marital conflict cause child maladjustment? Directions and challenges for longitudinal research. J Fam Psychol 1994; 8: 128-40.

[35] Gable S, Belsky J, Crnic K. Marriage, parenting, and child development: Progress and prospects. J Fam Psychol 1992; 5: 276-94.

[36] Zimet DM, Jacob T. Influences of marital conflict on child adjustment: review of theory and research. Clin Child Fam Psychol Rev 2002; 4: 319-35.

[37] Dunn J, Deater-Deckard K, Pickering K, Golding J, and the ALSPAC Study Team. Siblings, parents, and partners: Family relationships within a longitudinal community study. J Child Psychol Psychiatry 1999; 40: 1025-37.

[38] Fine MA, Kurdek LA. Relation between marital quality and (step)parent-child relationship quality for parents and stepparents in stepfamilies. J Fam Psychol 1995; 9: 216-23.

[39] Bond DD, Gondoli DM. Examining the process by which marital adjustment affects maternal warmth: The role of coparenting support as a mediator. J Fam Psychol 2007; 21: 288-96.

[40] Brody GH, Arias I, Fincham FD. Linking marital and child attributions to family processes and parent-child relationships. J Fam Psychol 1996; 10: 408-21.

[41] O'Brien M, Peyton V. Parenting attitudes and marital intimacy: A longitudinal analysis. J Fam Psychol 2002; 16: 118-27.

[42] Parker GB, Tupling H, Brown LB. A parental and bonding instrument. Br J Med Psychol 1979; 52: 1-10.

[43] Kitamura T, Suzuki T. A validation study of Parental Bonding Instrument in Japanese Population. Jpn J Psychiatry Neurol 1993; 47: 29-36.
[44] Uji M, Tanaka N, Shono M, Kitamura T. Factorial structure of the Parental Bonding Instrument (PBI) in Japan: A study of cultural, developmental, generational, and sexual influences. Child Psychiatry Hum Dev 2006; 37: 115-32.

[45] Wilhelm K, Parker G. The development of a measure of intimate bonds. Psychol Med 1988; 18: 225-34.

[46] Mulder RT, Joyce PR, Sullivan PF, Oakley-Browne MA. Intimate bonds in depression. J Affect Dis 1996; 40: 175-8.

[47] Yamada A, Suzuki M, Kato M, et al. Emotional distress and its correlates among parents of children with pervasive developmental disorders. Psychiatry Clin Neurosci 2007; 61: 651-7.

[48] Boyce P, Hickie I, Parker G. Parents, partners or personality? Risk factors for post-natal depression. J Affect Dis 2002; 21: 245-55.

[49] Hickie I, Parker G. The impact of an uncaring partner on improvement in non-melancholic depression. J Affect Dis 2002; 25: 14760 .

[50] Schermelleh-Engel1 K, Moosbrugger H, Müller H. Evaluating the fit of structural equation models: tests of significance and descriptive goodness-of-fit measures. Methods Psychol Res Online 2003; 8: 23-74.

[51] Robinson EA, Anderson LL. Family adjustment, parental attitudes, and social desirability. J Abnorm Child Psychol 1983; 11: 247-56.

[52] Fagot BI, Kavanagh K. Parenting during the second year: Effects of children's age, sex, and attachment classification. Child Dev 1993; 64: 258-71.

[53] Diekstein S, Parke RD. Social referencing in infancy: A glance at fathers and marriage. Child Dev 1988; 59: 506-11.

[54] Kerig PK, Cowan PA, Cowan PC. Marital quality and gender differences in parent-child interaction. Dev Psychol 1993; 29: 931-9.

[55] Kitamura T, Watanabe M, Aoki M, Fujino M, Ura C, Fujihara S. Factorial structure and correlates of marital adjustment in a Japanese population. J Commun Psychol 1995; 23: 117-26. 